\title{
New Model for Portfolio selection; based on Future approach (SFMADM)
}

\author{
Reza Mirbagheri ${ }^{1}$, Reza Roshangarzadeh ${ }^{2}$, Siamak Haji Yakhchali ${ }^{3}$
}

\begin{abstract}
Managers face many problems with regard to the relation between organization's strategies and organization's projects, which affect their approaches to decision making process. Selecting a portfolio of projects is an organizational long-term decision, so the integration of selecting a portfolio with organization's vision and also the probable scenarios should be guaranteed. This paper, by using a novel approach to calculate the decision matrix with regard to the impact of probable scenarios on both sides of alternatives and criteria, selects the best project portfolio by deploying the Fuzzy VIKOR method.
\end{abstract}

Keywords-Portfolio management, project selection, foresight, Multi Attribute Decision Making.

\section{INTRODUCTION}

Project portfolio management, which has been the focal center of interest for more than four decades, can be defined as to manage a group of projects concurrently and treat them as one unified object [1], [2]. Within this unified entity, the scarce resources are shared between the projects and an organization is in charge of managing this portfolio [3]. Project portfolio management consists of processes to make sure that there is a congruity between existing resources and the ability to manage the projects within a portfolio [4].

\section{A. Significance of portfolio management}

Due to the complex and globalized world we are dealing with, the problem of scheduling and selecting projects is of paramount importance [5]. Portfolio management is necessary to be implemented for the sake of decision making in projects, because the dire repercussions of poor decision making can be expensive [6]. It is obvious that with regard to dearth of resources, selecting the right projects as a portfolio is very important for organizations [5]. The significance of project portfolio management is heavily related to the notion of strategy. While performing projects to meet their planned time, cost and scope is important, but performing the appropriate

\footnotetext{
${ }^{1}$ Reza Mirbagheri/ student, Industrial Engineering Department, University of Tehran, IRAN, (e-mail: Rezamirbagheri@ut.ac.ir)

2 Reza roshangarzadeh/ student, Industrial Engineering Department, University of Tehran, IRAN, (e-mail: reza.st.ac@gmail.com).

3 Siamak Haji Yakhchali (Ph.D.) Assistant Professor, Industrial Engineering Department University of Tehran, IRAN, (e-mail: yakhchali@ut.ac.ir ).
}

projects to meet the strategic goals is also of paramount importance [7]. In this way, the proper portfolio management should be established to make sure of congruence between evaluation, prioritization and selection of projects at one hand and organizational strategy at the other hand [4]. According to a report, $66 \%$ of corporate strategies will never be implemented, because the main emphasis has always been on designing the best strategies rather than the methods to implement them (Morris and Jamieson, 2005). So, investigating the project portfolio management merits further attention as part and parcel of implementing organizational strategies [4].

\section{B. Portfolio selection methods}

Due to the importance and prevalence of project portfolio management in project-based organizations, different criteria have been considered for selecting the project portfolios and in turn, various Multi-Criteria Decision Making (MCDM) techniques have been developed.

MCDM models have been formulated to prioritize a set of alternatives with respect to multiple criteria. In the realm of MCDM methods, two categories received greater publicity, namely Multiple Criteria Decision Making (MADM) and Multiple Objective Decision Making (MODM). MADM techniques, which can be defined as sorting the alternatives with regard to a finite set of criteria, have been applied to many studies in the field of portfolio selection. Methods such as ANP [9], AHP [10], TOPSIS [11], VIKOR [12], MOORA [13] are some of these applications. MODM techniques have been designed to determine the best alternatives by doing mathematics with the aid of objective functions, when the alternatives are not clearly given [14]. There are few studies which investigated the project portfolio selection with using these methods [5], [10]. In this paper, the alternatives have been given, so MADM techniques are more suitable to be pursued.

\section{C.Problem description}

There are few studies probing the relation between strategy, project portfolio management and business success. Muller et al. indicated that there is a positive linkage between the performance of a portfolio and the strategies designed to conform portfolio selection and also the business-level results [4], [15]. Some studies investigated only a segment of portfolio management, for example, the role of project prioritization as a key factor for organizations' success [4]. But 
there are a very few studies to examine the whole processes of portfolio management and its impact on business success [3].

As mentioned before, researchers have been applying MCDM techniques for the subject of project portfolio selection, But the problem about using them is neglecting future and observing everything retrospectively. It is very obvious that we are living in a changing world, and sometimes these changes will be extremely abrupt. This simple fact begs the question of how it is possible to insert these probable changes in the future to our decision making process (Scenario-based approach). To do so, few researchers have proposed new methods, like $\mathrm{PMADM}^{4}$ [16] and $\mathrm{SPM}^{5}$ [17]. With this regard, we intend to implement a project portfolio selection by using a foresight approach in an IT-based corporation. To test the effectiveness of the method, it was implemented in an IT-based corporation, due to the fact that IT is now experiencing far-reaching changes compared to other sections. The results show a greater degree of integration between different organization's sections and also a long-term mutual vision in the corporation for selecting the project portfolios was created.

\section{D. contributions}

The contributions of this paper can be enumerated as following:

- Using foresight-based approach to cover the future uncertainties

- Introducing a quantitative approach to calculate the probabilities of the scenarios

- Considering the impacts of scenarios on alternatives and criteria separately to avoid vague and inconsistent judgments by the experts

- Using fuzzy approach to cover the uncertainties stem from the limited knowledge

- Using an integrated system of Fuzzy Best-Worst Method and Fuzzy VIKOR to form the decision making approach

The rest of the paper is organized in the following way: Section II is dedicated to the suggested method for defining the scenario, determining the weighting vector and portfolio selection. Section III empirical data and conclusion will be presented in section IV.

\section{PROPOSED MODEL}

\section{A. SFMADM ${ }^{6}$ model}

As it was mentioned, this paper intends to apply a foresight approach for choosing the best project portfolios and this objective will be pursued by using an extension of PMADM [16]. In order to incorporate future studies into the MADM models, generally speaking, two approaches can be implemented, namely identification of future limiters with the aid of experts' opinions, and determining future scenarios based on scenario planning workshops [16]. Future limiters are usually limited to local matters for the corporation, like the

\footnotetext{
${ }^{4}$ Prospective Multiple Attribute Decision Making

${ }_{6}^{5}$ Scenario-based Planning Method

${ }^{6}$ Scenario-based Fuzzy Multi Attribute Decision Making
}

budget limitation, human resources limitation and so on. On the contrary, future scenarios are usually delving into the more macro level matters, such as climate change, wars, deflation in oil price and so on. This paper is dedicated to study project portfolio selection in a macro level, so the future scenarios will be more apposite to this goal.

The scenarios which can affect the organizations' status are usually determined in a formal meeting of the top tier managers. It is not a formidable task to determine the priority of scenarios, but when it comes to allocating an exact number directly to a scenario as its probability of happening, the story is different [18]. To be ensured of lacking any substantial bias in the process of determining the probability of scenarios, SWARA methods, as an efficient subjective MADM technique will be deployed [19]. This method only necessitates sorting the scenarios based on their probabilities of happening and determining a few relative pairwise comparisons. A concise version of this method is introduced in the following and the interested readers can refer to [19] for delving deeply into this method.

Step 1: prioritizing the criteria based on their importance

Step 2: determining the $S_{j}$ as the relative pairwise importance of criterion $c_{j}$ compared to $c_{j-1}$

Step 3: calculating the $w_{j}$ as the weight of criterion $\mathrm{j}$ according to following formulas:

$$
w_{j}=\frac{w_{j-1}}{S_{j}+1}
$$

Step 4: normalizing the obtained weights through linear normalization.

Now, the probability of each scenario is obtained.

\section{B. Decision matrix}

Regarding future study for solving a decision making problem entails adding a new factor to the decision matrix. The scenarios as the new factor would affect both sides of decision matrices. In other words, it is not staggering that the future uncertainties have an impact on alternatives and criteria and this impact can change the process of decision making so drastically. Owing to the intricacy of considering three separate factors concurrently for decision making and the possible errors and imprecision of doing this, a new method is developed to overcome this hurdle. To do this, we consider the impact of scenarios on the alternatives and also the criteria separately, and then with regard of the probability of scenarios, the final decision matrix will be obtained. To negate the adverse effects of imprecision, vagueness and incompletion, we use triangular fuzzy numbers to form the decision matrix.

Suppose that $\tilde{a}_{i k}$ and $\tilde{c}_{j k}$ denote the judgement of the i-th alternative and the judgment of the $\mathrm{j}$-th criterion with regard to the k-th scenario in the form of linguistic variables, respectively. $p\left(s_{k}\right)$ is assumed to represent the probability of 
the k-th scenario. The following formulas calculate the fuzzy decision matrix:

$$
\begin{gathered}
A=\left[\tilde{a}_{i k}\right]_{m \times o} \\
C=\left[\tilde{c}_{j k}\right]_{n \times o} \\
P=\left[\begin{array}{cccc}
p\left(s_{1}\right) & p\left(s_{1}\right) & \cdots & p\left(s_{1}\right) \\
p\left(s_{2}\right) & p\left(s_{2}\right) & \cdots & p\left(s_{2}\right) \\
\cdots & \ldots & \cdots & \ldots \\
p\left(s_{o}\right) & p\left(s_{o}\right) & \cdots & p\left(s_{o}\right)
\end{array}\right]_{o \times o} \\
\tilde{D}=\left[\tilde{x}_{i j}\right]_{m \times n}=A \times P \times C^{T}
\end{gathered}
$$

It should be noted that the product between matrices is the usual matrix product, with the difference that the product of two elements should be the usual product of triangular fuzzy numbers.

\section{Obtaining weighting vector of criteria}

There are many MADM methods to do this, like AHP, ANP and so on, But the majority of these well-known methods need a lot of pairwise comparisons and calculations, so the possible errors would be abundant [20]. Experts usually determine the best criterion and the worst criterion in their mind, and then try to allocate numbers to other criteria to the degree that their judgments do not infringe the best and the worst criterion. There is a method that models this mind process and also reduces the time-consuming problem of calculating many matrices, called Best-Worst Method. For the sake of preventing any substantial vagueness, imprecision and incompletion of judgments, the Fuzzy version will be deployed [21]. This method has many details, so interested readers can refer to the paper [21] to have a profound knowledge of this method.

Suppose that $\tilde{a}_{B j}$ and $\tilde{a}_{j W}$ denote the expert's judgment about the criterion $\mathrm{j}$ compared with the best and the worst criteria respectively.

$$
\begin{aligned}
& \tilde{w}_{j}=\left(l_{j}^{w}, m_{j}^{w}, u_{j}^{w}\right) \\
& \tilde{a}_{B j}=\left(l_{B j}, m_{B j}, u_{B j}\right) \\
& \tilde{a}_{j W}=\left(l_{j W}, m_{j W}, u_{j W}\right) \\
& \tilde{\xi}^{*}=\left(k^{*}, k^{*}, k^{*}\right)
\end{aligned}
$$

The optimal weights $\tilde{w}_{j}$ are obtained by solving the fuzzy nonlinear programming presented below: $\min \tilde{\xi}^{*}$

s.t.

$$
\left\{\begin{array}{c}
\left|\frac{\left(l_{B}^{w}, m_{B}^{w}, u_{B}^{w}\right)}{\left(l_{j}^{w}, m_{j}^{w}, u_{j}^{w}\right)}-\tilde{a}_{B j}\right| \leq\left(k^{*}, k^{*}, k^{*}\right) \\
\left|\frac{\left(l_{j}^{w}, m_{j}^{w}, u_{j}^{w}\right)}{\left(l_{W}^{w}, m_{W}^{w}, u_{W}^{w}\right)}-\tilde{a}_{j W}\right| \leq\left(k^{*}, k^{*}, k^{*}\right) \\
\sum_{j=1}^{n} R\left(\tilde{w}_{j}\right)=1 \\
l_{j}^{w} \leq m_{j}^{w} \leq u_{j}^{w} \\
l_{j}^{w} \geq 0 \\
j=1,2, . . n
\end{array}\right.
$$

\section{Choosing the best portfolio}

To do so, some methods have been developed, such as AHP, ANP, BWM, TOPSIS, VIKOR and so on. Analytic methods like AHP, ANP and BWM are usually deemed to determine the weighting vector of criteria [22]. But in order to choose the best alternatives, different methods are deployed. Owing to the fact that organizations wish to reach the best possible performance, specific MADM methods have been evolved to satisfy this ambition, such as TOPSIS and VIKOR. Both methods have been designed to determine the best value and the worst value of criteria and then identify the best and the worst solutions. The other solutions will be prioritized according to their distance to the best and the worst solutions. TOPSIS method selects alternatives with closest distance to the best solution while having longest distance from the worst solution. The problem with this method is that it treats the importance of distance from the best solution and the importance of worst solution as equal. But the fact is that sometimes it is more important to be close to the best solution than be far from the worst solution, and this is the underlying assumption of the VIKOR method [23]. According to previous mentioned advantages of fuzzy approach in decision making process, the Fuzzy VIKOR is applied [22]. The following steps give a succinct explanation of how this method works:

Suppose that $\tilde{x}_{i j}=\left(\tilde{l}_{i j}, \tilde{m}_{i j}, \tilde{u}_{i j}\right)$ denotes an arbitrary element of the decision matrix, then $\tilde{f}_{j}^{-}$and $\tilde{f}_{j}^{*}$ are calculated as

$$
\tilde{f}_{j}^{*}=\left(l_{j}^{*}, m_{j}^{*}, u_{j}^{*}\right)=\left(\max _{j} l_{i j}, \max _{j} m_{i j}, \max _{j} u_{i j}\right)
$$

$\tilde{f}_{j}^{-}=\left(l_{j}^{-}, m_{j}^{-}, u_{j}^{-}\right)=\left(\min _{j} l_{i j}, \min _{j} m_{i j}, \min _{j} u_{i j}\right)$

Then, the index values $\tilde{S}_{i}, \tilde{R}_{i}$ and values $\tilde{Q}_{i}$ are calculated as

$$
\tilde{S}_{i}=\left(S_{i}^{l}, S_{i}^{m}, S_{i}^{u}\right)=\sum_{j=1}^{n} \oplus \tilde{w}_{j} \otimes \frac{\tilde{f}_{j}^{*}-\tilde{x}_{i j}}{u_{j}^{*}-l_{j}^{-}}
$$




$$
\begin{gathered}
\tilde{R}_{i}=\left(R_{i}^{l}, R_{i}^{m}, R_{i}^{u}\right)=\max _{j} \tilde{w}_{j} \otimes \frac{\tilde{f}_{j}^{*}-\tilde{x}_{i j}}{u_{j}^{*}-l_{j}^{-}} \\
\tilde{Q}_{i}=\left(Q_{i}^{l}, Q_{i}^{m}, Q_{i}^{u}\right)=v \frac{\tilde{S}_{i}-\tilde{S}_{\min }}{S_{\text {max }}^{u}-S_{\text {min }}^{l}} \oplus(1-v) \frac{\tilde{R}_{i}-\tilde{R}_{\min }}{R_{\text {max }}^{u}-R_{\text {min }}^{l}}
\end{gathered}
$$

values will be defuzzified to form $S_{i}, R_{i}$ and $Q_{i}$ by using following formula:

$$
x_{i j}=\frac{l_{i j}+m_{i j}+u_{i j}}{3}
$$

With regard to having the crisp values at hand, the rest of the steps is same as the original VIKOR model [22].

\section{IMPLEMENTATION OF THE MODEL IN A REAL CASE}

In order to test the proposed model, it was implemented in an IT-based corporation to select the best project portfolio. It is inevitable to have a unanimous perspective between the members of the decision making team to determine the set of policies to be pursued. This corporation is in the business of developing social networks to be applicable in smart phones.

With regard to using a foresight-based approach and scenario planning, probable scenarios have been found after a scenario planning workshop held by the top tier of managers, such as CEO, CMO, CTO. These scenarios are listed as below:

- Scenario 1: Abrupt changes in the popular programming languages used for mobiles

- Scenario 2: Changes in the regulations at a macro level, such as filtering regulations and facilitating the regulations for entrance of foreign companies in this field by the government

- Scenario 3: Changes of executive managers and members of the Board of directors, so the possibility of focusing on a different approach to address this field

The probabilities of these scenarios, $p\left(s_{k}\right)$, have been calculated based on SWARA method and are presented in table 1 .

TABLE I: PROBABILITIES OF THE SCENARIOS

\begin{tabular}{|c|c|c|c|}
\hline Ordered scenarios & $S_{j}$ & $w_{j}$ & Normalized $w_{j}$ \\
\hline Scenario 1 & - & 1 & 0.52 \\
\hline Scenario 3 & 0.8 & 0.55 & 0.29 \\
\hline Scenario 2 & 0.5 & 0.37 & 0.19 \\
\hline
\end{tabular}

This corporation, as a leading corporation in the business of social networks' development, has defined five portfolios of projects, namely, developing Android-based version (A1), IOS-based version (A2), Desktop-based version (A3), Webbased version (A4), and Transaction payment-based version (A5) as the alternatives. The specific criteria have been determined to assess these alternatives, namely the human resources $(\mathrm{C} 1)$, cost $(\mathrm{C} 2)$, brand reputation $(\mathrm{C} 3)$ and the duration of the portfolio (C4).
According to experts' opinions, the brand reputation (C3), due to its great contribution to boost competitive advantage, and the duration $(\mathrm{C} 4)$ have been labeled as the best and the worst criteria. The following table presents the relative

\begin{tabular}{|c|c|c|c|c|}
\hline & $\begin{array}{l}\mathrm{C} \\
1\end{array}$ & $\mathrm{C} 2$ & C3 & $\mathrm{C} 4$ \\
\hline C3 & FI & FI & EI & WI \\
\hline C4 & $\overline{\text { FI }}$ & WI & WI & EI \\
\hline
\end{tabular}
importance, based on the transformation table from paper [21]

TABLE II: PAIRWISE COMPARISONS ACCORDING TO EXPERTS' OPINIONS

So, based on solving the model which was mentioned in the Fuzzy Best-Worst section, the optimal weights $\widetilde{w}_{j}$ are obtained as below:

TABLE III: FuZZy BWM weIGHTS
\begin{tabular}{|c|c|}
\hline Index & $\begin{array}{c}\text { Optimal weights } \\
\left(\tilde{w}_{j}\right)\end{array}$ \\
\hline C 3 & $(0.331,0.367,0.431)$ \\
\hline C 1 & $(0.239,0.258,0.313)$ \\
\hline C 2 & $(0.165,0.198,0.283)$ \\
\hline C 4 & $(0.147,0.152,0.195)$ \\
\hline
\end{tabular}

Based on experts' opinions, the matrices $\mathrm{A}$ and $\mathrm{C}$ are given as below:

$$
A=\left[\begin{array}{ccc}
N & P & L \\
L & V H & L \\
H & M & N \\
V H & N & N \\
P & P & L
\end{array}\right], C=\left[\begin{array}{ccc}
P & N & V H \\
M & L & H \\
L & P & L \\
P & V H & L
\end{array}\right]
$$

With the aid of transformation table of paper [22] and the equation (5), the decision matrix, $\tilde{D}$, can be calculated as the following table indicates:

TABLE IV: FUZZY DECISION MATRIX

\begin{tabular}{|c|c|c|c|c|}
\hline & $\mathrm{C}_{1}$ & $\mathrm{C}_{2}$ & $\mathrm{C}_{3}$ & $\mathrm{C}_{4}$ \\
\hline $\mathrm{A}_{1}$ & $(0.02,0.05,0.23)$ & $(0.06,0.14,0.28)$ & $(0.21,0.311,0.40)$ & $(0.17,0.26,0.43)$ \\
\hline $\mathrm{A}_{2}$ & $(0.10,0.22,0.40)$ & $(0.08,0.21,0.4)$ & $(0.18,0.35,0.51)$ & $(0.21,0.39,0.6)$ \\
\hline $\mathrm{A}_{3}$ & $(0.22,0.35,0.5)$ & $(0.10,0.22,0.41)$ & $(0.12,0.32,0.50)$ & $(0.28,0.47,0.64)$ \\
\hline $\mathrm{A}_{4}$ & $(0.29,0.43,0.56)$ & $(0.11,0.22,0.40)$ & $(0.06,0.22,0.41)$ & $(0.29,0.43,0.59)$ \\
\hline $\mathrm{A}_{5}$ & $(0.38,0.57,0.66)$ & $(0.20,0.40,0.57)$ & $(0.28,0.57,0.69)$ & $(0.52,0.78,0.86)$ \\
\hline
\end{tabular}

Now, by applying the Fuzzy VIKOR and through using Equations (8) to (12), the following table is obtained with the assumption that $v$ is equal to 0.5 .

TABLE V:VIKOR RESULT

\begin{tabular}{|c|c|c|c|}
\hline \multirow{2}{*}{ Alternative } & $Q_{i}$ & $S_{i}$ & $R_{i}$ \\
\hline A1 & 0.36 & 0.56 & 0.20 \\
\hline A2 & 0.25 & 0.36 & 0.16 \\
\hline A3 & 0.21 & 0.18 & 0.17 \\
\hline A4 & 0.22 & 0.07 & 0.21 \\
\hline A5 & 0.00 & -0.11 & 0.07 \\
\hline
\end{tabular}


A simple calculation will illuminate that the two conditions of the Fuzzy VIKOR are satisfied, so the A5, developing transaction payment-based version is the best solution for this corporation.

\section{CONCLUSION}

Owing to the highly competitive environment of IT area, redefining the notion of sustainable competitive advantage for corporations is necessary. Simultaneous with the social networks' growth, many corporations have made many attempts to develop these networks on different platforms. In this very case, the important scenarios have been agreed upon by the top managers and for the first time by using SWARA as an effective MADM technique, the probabilities of these scenarios have been calculated. Moreover, the future uncertainties and vagueness have been introduced in the model by using fuzzy linguistic variables in assessing the alternatives and criteria based on the scenarios. The results indicated that this corporation should support a unique, almost inimitable competitive advantage to boost its brand by pursuing the development of transaction payment-based networks.

\section{V.REFERENCES}

[1] S. Iamratanakul, P. Patanakul, and D. Milosevic, "Project portfolio selection: From past to present," in 2008 4th IEEE International Conference on Management of Innovation and Technology, 2008, pp. 287-292.

[2] P. Patanakul and D. Milosevic, "The effectiveness in managing a group of multiple projects: Factors of influence and measurement criteria," Int. J. Proj. Manag., vol. 27, no. 3, pp. 216-233, Apr. 2009.

[3] N. P. Archer and F. Ghasemzadeh, "An integrated framework for project portfolio selection," Int. J. Proj. Manag., vol. 17, no. 4, pp. 207-216, Aug. 1999.

[4] S. Meskendahl, "The influence of business strategy on project portfolio management and its success - A conceptual framework," Int. J. Proj. Manag., vol. 28, no. 8, pp. 807-817, Dec. 2010.

[5] F. Perez and T. Gomez, "Multiobjective project portfolio selection with fuzzy constraints," Ann. Oper. Res., vol. 245, no. 1-2, pp. 7-29, Oct. 2016.

[6] K. Benaija and L. Kjiri, "Hybrid approach for project portfolio selection based on the business strategy and the scoring model," in Fifth International Conference on the Innovative Computing Technology (INTECH 2015), 2015, pp. 106-111.

[7] J. Wen, "The Strategy-Oriented Project Portfolio Selection and Management," in 2010 International Conference on E-Product EService and E-Entertainment, 2010, pp. 1-4.

[8] N. H. Zardari, K. Ahmed, S. M. Shirazi, and Z. B. Yusop, Weighting Methods and their Effects on Multi-Criteria Decision Making Model Outcomes in Water Resources Management. Springer International Publishing, 2015.

[9] F. Aliakbari Nouri, S. Khalili Esbouei, and J. Antucheviciene, "A Hybrid MCDM Approach Based on Fuzzy ANP and Fuzzy TOPSIS for Technology Selection," Informatica, vol. 26, no. 3, pp. 369-388, Jan. 2015.

[10] E. Gomede and R. M. de Barros, "A multicriteria approach to project portfolio selection: Using multiobjective optimization and Analytic Hierarchy Process," in 2014 9th Iberian Conference on Information Systems and Technologies (CISTI), 2014, pp. 1-7.

[11] M. Babaei, M. Maleki, and M. Moradi, "Integration of Fuzzy MCDM Methods for Portfolio Selection," Glob. J. Manag. Stud. Res., vol. 2, no. 3, pp. 179-186, Jan. 2016.

[12] M. Gul, E. Celik, N. Aydin, A. Taskin Gumus, and A. F. Guneri, "A state of the art literature review of VIKOR and its fuzzy extensions on applications," Appl. Soft Comput., vol. 46, pp. 60-89, Sep. 2016.
[13] P. Karande and S. Chakraborty, "A Fuzzy-MOORA approach for ERP system selection," Decis. Sci. Lett., vol. 1, no. 1, pp. 11-21, 2012.

[14] C. Kahraman, Fuzzy multi-criteria decision making: theory and applications with recent developments, vol. 16. Springer Science \& Business Media, 2008.

[15] R. Müller, M. Martinsuo, and T. Blomquist, "Project portfolio control and portfolio management performance in different contexts," Proj. Manag. J., vol. 39, no. 3, pp. 28-42, Sep. 2008.

[16] S. H. Zolfani, R. Maknoon, and E. K. Zavadskas, "An introduction to Prospective Multiple Attribute Decision Making (PMADM)," Technol. Econ. Dev. Econ., vol. 22, no. 2, pp. 309-326, Mar. 2016.

[17] P. Zhang, K. Yang, Y. Dou, and J. Jiang, "Scenario-based approach for project portfolio selection in army engineering and manufacturing development," J. Syst. Eng. Electron., vol. 27, no. 1, pp. 166-176, Feb. 2016.

[18] M. Amer, T. U. Daim, and A. Jetter, "A review of scenario planning," Futures, vol. 46, pp. 23-40, Feb. 2013.

[19] S. Hashemkhani Zolfani, J. Salimi, R. Maknoon, and S. Kildiene, "Technology Foresight About R\&D Projects Selection; Application of SWARA Method at the Policy Making Level," Eng. Econ., vol. 26, no. 5, pp. 571-580, Dec. 2015.

[20] J. Rezaei, "Best-Worst Multi-Criteria Decision-Making Method," Omega, vol. 53, pp. 49-57, 2015.

[21] S. Guo and H. Zhao, "Fuzzy best-worst multi-criteria decision-making method and its applications," Knowl.-Based Syst., vol. 121, pp. 2331, Apr. 2017.

[22] Z. Wu, J. Ahmad, and J. Xu, "A group decision making framework based on fuzzy VIKOR approach for machine tool selection with linguistic information," Appl. Soft Comput., vol. 42, pp. 314-324, May 2016.

[23] S. Opricovic and G.-H. Tzeng, "Extended VIKOR method in comparison with outranking methods," Eur. J. Oper. Res., vol. 178, no. 2, pp. 514-529, Apr. 2007. 